\title{
CARACTERES ANATÔMICOS DE FOLHA DE Vernonanthura tweedieana (BAKER) H.ROB., ASTERACEAE
}

\author{
ANATOMICAL CHARACTERS OF THE LEAF OF \\ Vernonanthura tweedieana (BAKER) H.ROB., ASTERACEAE
}

\author{
DUARTE, M. R..$^{*} ;$ CHELLA, L. ${ }^{2}$ \\ ${ }^{1}$ Laboratório de Farmacognosia, Departamento de Farmácia, Universidade Federal do Paraná (UFPR), \\ ${ }^{2}$ Bolsista PIBIC/CNPq, Curso de Farmácia, UFPR \\ *Autor para correspondência: Márcia R. Duarte. E-mail: marciard@ufpr.br
}

\begin{abstract}
RESUMO:
A espécie Vernonanthura tweedieana, anteriormente referida pelo basiônimo Vernonia tweediana, é denominada comumente de assa-peixe e empregada para tratar distúrbios respiratórios e como antimicrobiano na medicina popular. Este trabalho objetivou investigar a anatomia foliar dessa planta medicinal, a fim de subsidiar a identificação microscópica no controle de qualidade farmacognóstico. O material botânico foi coletado, identificado e preparado de acordo com técnicas usuais para observação em microscopia de luz e eletrônica de varredura. A folha é anfiestomática, exibindo estômatos anomocíticos em maior número na face abaxial. Ocorrem tricomas tectores e glandulares. Os primeiros são pluricelulares, unisseriados, com célula apical alongada. Os tricomas glandulares são capitados, com pedicelo curto e cabeça bicelular. A epiderme é unisseriada e o mesofilo é dorsiventral. A nervura central e o pecíolo são percorridos por vários feixes vasculares colaterais, dispostos lado a lado. Esses resultados são inéditos para a espécie e contribuem para a sua caracterização microscópica.
\end{abstract}

Palavras-chave: controle de qualidade, farmacobotânica, microscopia, planta medicinal, Vernonia tweediana

\begin{abstract}
:
The species Vernonanthura tweedieana, formerly referred by its basionym Vernonia tweediana, is usually known as assa-peixe in Portuguese. It is used to treat respiratory upsets and as an antimicrobial agent in folk medicine. This work aimed to investigate the leaf anatomy of this medicinal plant, in order to favor the microscopic identification for the pharmacognostic quality control. The plant material was collected, identified and prepared according to standard techniques for light and scanning electron microscopy. The leaf is amphistomatic, having anomocytic stomata predominantly on the abaxial side. There are non-glandular and glandular trichomes. The former are multicellular, uniseriate with a long apical cell. The glandular trichomes are capitate, consisting of a short stalk and bicellular head. The epidermis is uniseriate and the mesophyll is dorsiventral. The midrib and petiole are traversed by various collateral vascular bundles arranged side by side. These results are a novelty for the species and contribute to its microscopic diagnosis.
\end{abstract}

Keywords: medicinal plant, microscopy, morpho-anatomy, quality control, Vernonia tweediana 


\section{INTRODUÇÃO}

A espécie Vernonanthura tweedieana (Baker) H.Rob., Asteraceae, anteriormente referida pelo basiônimo Vernonia tweediana Baker (IPNI, 2014; MOBOT, 2014), é uma planta subarbustiva conhecida comumente como assa-peixe (MARODIN, BAPTISTA, 2001) e mata-pasto (SOARES et al., 2004). De acordo com Robinson (1992), o gênero Vernonanthura segregou-se de Vernonia e inclui espécies neotropicais distribuídas desde o México à Argentina, que exibem caule ereto e anteras frequentemente com prolongamento basal, entre outras características diferenciais.

$\mathrm{Na}$ medicina popular, $V$. tweedieana é empregada para tratar distúrbios respiratórios, notadamente pelas propriedades expectorantes (ZANON, 2006), e como antiparasitário (SOARES et al., 2004), antimicrobiano e cicatrizante (PORTILLO et al., 2005). Investigações fitoquímicas isolaram dessa planta medicinal triterpenos, tais como $\alpha$ - e $\beta$-amirinas e lupeol, esteroides como $\beta$-sitosterol, estigmasterol e espinasterol, e o flavonoide eriodictiol (ZANON, 2006).

A exemplo de espécies correlatas cujos efeitos farmacológicos foram comprovados, a saber, polissacarídeos imunomoduladores de Vernonia kotschyana Sch.Bip. ex Walp. (NERGARD et al., 2004), ação antibacteriana de lactonas sesquiterpênicas de Vernonia colorata (Willd.) Drake (RABE, MULLHOLLAND, STADEN, 2002) e atividades analgésica, antipirética e anti-inflamatória de Vernonia cinerea (L.) Less. (IWALEWA, IWALEWA, ADEBOYE, 2003), V. tweedieana tem despertado o interesse de grupos de pesquisadores de diferentes áreas. Procurando contribuir para o incremento do conhecimento a respeito dessa promissora droga vegetal, este trabalho objetivou estudar os caracteres anatômicos de folha, com vistas a facilitar a identificação de $V$. tweedieana no controle de qualidade farmacognóstico.

\section{MATERIALE MÉTODOS}

\subsection{MATERIAL BOTÂNICO}

O material vegetal foi proveniente de espécimes de $V$. tweedieana coletados em fevereiro de 2005 da flora espontânea em Palotina, município do oeste do Paraná (coordenadas $24^{\circ} 17^{\prime} \mathrm{S}$ e $53^{\circ} 40^{\prime} \mathrm{W}$ e altitude de $290 \mathrm{~m}$ ). Uma exsicata foi identificada e depositada no Museu Botânico Municipal de Curitiba sob registro MBM 301462.

\subsection{METODOLOGIA}

Folhas plenamente desenvolvidas, coletadas a partir do sexto nó caulinar, foram fixadas em FAA70 (JOHANSEN, 1940) e armazenadas em etanol a $70 \%$ 
(BERLYN, MIKSCHE, 1976) para serem posteriormente preparadas e analisadas por meio de microscopia fotônica (MF) e eletrônica de varredura (MEV).

Lâminas semipermanentes (MF) foram feitas com o material foliar seccionado à mão livre, nos sentidos transversal e paradérmico, corado com azul de astra e fucsina básica (ROESER, 1972) e montado com glicerina a 50\% (MACÊDO, 1997). Confeccionaram-se lâminas permanentes (MF) com o material desidratado em série etanólica crescente, emblocado em glicol-metacrilato, seccionado em micrótomo de rotação, corado com azul de toluidina (O'BRIEN, FEDER, McCULLY, 1964) e montado com resina sintética(MACÊDO, 1997).

Paralelamente, para a verificação dos caracteres ultraestruturais de superfície (MEV), fragmentos fixados de folha foram desidratados em gradiente etanólico e pelo ponto crítico de $\mathrm{CO}_{2}$, metalizados com ouro e observados em alto vácuo (SOUZA, 1998).

\section{RESULTADOS}

Em vista frontal da região internervural do limbo, a epiderme exibe células com paredes anticlinais praticamente retas na face adaxial (Figura 1A) e onduladas na superfície oposta (Figura 1B). Revestindo a epiderme, ocorre uma cutícula levemente ornamentada, que apresenta estriações mais evidentes nas proximidades dos estômatos (Figuras 1C, 1D). Estes se localizam em ambas as faces epidérmicas, com maior predomínio na abaxial, em distribuição anfiestomática, e são classificados como anomocíticos (Figuras 1A, 1B), categoria na qual as células-guarda são ladeadas por três ou mais células com morfologia semelhante às demais células epidérmicas.

Diferentes tipos de tricomas estão presentes: glandulares e tectores (Figuras 1D-F, 2C). Os primeiros são capitados, com pedicelo curto e cabeça bicelular, inseridos em pequena depressão (Figura 2D). Os tectores são pluricelulares, unisseriados, exibindo uma célula apical alongada (Figuras $1 \mathrm{E}, 2 \mathrm{C}$ ), que pode se inclinar perpendicularmente e determinar um formato em "T" (Figuras 1F, 2C).

Em secção transversal (Figura 2A), a epiderme mostra-se unisseriada, sendo as células da face adaxial maiores que as da abaxial. A cutícula é relativamente delgada e os estômatos estão posicionados no mesmo nível que as células adjacentes. O mesofilo é dorsiventral e compreende um a três estratos de parênquima paliçádico e cerca de cinco camadas de parênquima esponjoso, havendo a presença de células coletoras conectando esses parênquimas clorofilianos. Feixes vasculares de pequeno porte distribuem-se no mesofilo e são envoltos por bainha parenquimática.

A nervura central mostra secção transversal biconvexa, com curvatura mais pronunciada na face abaxial (Figura 2B). Aepiderme possui as mesmas características da região internervural e há algumas camadas de colênquima angular-lacunar na 
sequência (Figuras 2B, 2C). Mergulhados no parênquima fundamental, encontram-se aproximadamente cinco feixes vasculares, de formato ovalado e distribuídos em semicírculo (Figura 2B). Os centrais são maiores e todos são do tipo colateral (Figura 2B), exibindo uma zona cambial evidente (Figura 2D).

O pecíolo tem contorno plano-convexo, quando seccionado transversalmente. A epiderme é unisseriada e, subjacente à mesma, encontra-se uma faixa contínua de colênquima angular. Vários feixes vasculares percorrem o parênquima fundamental e assumem disposição em "V" (Figura 3A). São ovalados, colaterais e mostram uma nítida zona cambial (Figura 3B).

\section{DISCUSSÃO}

Os caracteres anatômicos observados em $V$. tweedieana se enquadram entre aqueles atribuídos a Asteraceae (Compositae), família cujos representantes possuem considerável diversidade morfológica e química, pelo fato de distribuírem-se em diferentes habitats e apresentarem consequentes especializações ecológicas (METCALFE, CHALK, 1950). Portanto, a ocorrência de tricomas tectores e glandulares, estômatos anomocíticos em ambas as superfícies foliares, epiderme unisseriada, mesofilo dorsiventral e vários feixes vasculares colaterais percorrendo a nervura central e o pecíolo são caracteres usualmente descritos para as espécies da família.

Todavia, para Metcalfe e Chalk (1950), algumas estruturas possuem valor taxonômico, favorecendo a distinção entre representantes de grupos relacionados. Assim, a organização dos feixes vasculares no pecíolo se mostra relevante na distinção de espécies de Asteraceae, uma vez que muitas podem apresentar feixes dispostos em círculo ou múltiplos arcos. Esses arranjos considerados frequentes diferem da constatação feita neste trabalho, em que se verificou a presença de vários feixes vasculares dispostos em um único arco aberto em $V$. tweedieana.

Ainda, enfocando caracteres de valor diagnóstico, destaque deve ser dado a singularidades morfológicas dos tricomas, a exemplo dos tricomas tectores em forma de "T" observados nesta investigação. Esses anexos epidérmicos foram também descritos em Vernonanthura serratuloides (Kunth) H.Rob. (REDONDA-MARTíNEZ, VILLASEÑOR, TERRAZAS, 2012), em Vernonia brasiliana (L.) H.Rob. (FILIZOLA et al., 2003), bem como em Vernonia fulta Griseb., sendo referidos como tricomas malpighiáceos (ALBORNOZ et al., 2001) e em Vernonia condensata Baker sob a denominação de tricomas tectores do tipo "bigorna"(BARRETO, ALVES, NEVES, 1994). Todavia, há resultados controversos a respeito de $V$. condensata, uma vez que na investigação de Milan, Hayashi e Apezzato-da-Glória (2006) descrevem-se tricomas tectores e glandulares, porém sem menção do tipo tector em “T” ou bigorna. 
Com base na diversidade de tricomas em comum relatados em Vernonanthura e Vernonia, Redonda-Martínez, Villaseñor e Terrazas (2012) destacam que estes assumem valor taxonômico no nível de espécie, embora não possam ser utilizados na diagnose em nível de gênero.

Embora a espécie deste estudo exiba geralmente aspectos anatômicos semelhantes a Vernonia relacionadas, $V$. tweedieana pode ser distinguida de $V$. condensata pelo fato desta última possuir adicionalmente tricomas glandulares bisseriados e drusas na lâmina foliar (MILAN, HAYASHI, APEZZATO-DA-GLÓRIA, 2006). Essas características diferenciais acrescidas ainda de folha hipoestomática são encontradas em V. fulta(ALBORNOZ et al., 2001).

Comparativamente a outras espécies próximas, $V$. tweedieana diferencia-se de $V$. brasiliana, em razão desta apresentar folha hipoestomática e nervura central com três feixes vasculares (FILIZOLA et al., 2003). A ocorrência de estômatos exclusivamente na face abaxial e nervura central percorrida por um único feixe vascular pode ser utilizada para distinção de Vernonia scorpioides (Lam.) Pers. (ARAMBARRI et al., 2009). Com relação a Vernonia polyanthes Less. (JORGE, PEREIRA, SILVA, 1991), folha hipoestomática, drusas de oxalato de cálcio, feixes vasculares com calotas esclerenquimáticas e dutos laticíferos são elementos que possibilitam a distinção entre as duas espécies.

Conclusivamente, observa-se que os caracteres anatômicos descritos neste trabalho são inéditos para a espécie e, quando considerados em conjunto, são aplicáveis na distinção das espécies mencionadas. Adicionalmente, contribuem para a identificação microscópica de $V$. tweedieana na etapa inicial do controle de qualidade farmacognóstico.

\section{AGRADECIMENTOS}

Os autores são gratos a C.B. Empinotti pela coleta do material vegetal, a O.S. Ribas pela identificação da espécie, ao Centro de Microscopia Eletrônica (CME-UFPR) pelas micrografias de varredura e ao PIBIC/CNPq pela bolsa concedida a $\mathrm{L}$. Chella.

\section{REFERÊNCIAS}

ALBORNOZ, P.; MURUAGA, N.; BULACIO, E.; ARIAS, M. Anatomía foliar de Vernonia fulta (Asteraceae). Lilloa, Tucumán, v. 40, n. 2, p. 149-156, 2001.

ARAMBARRI, A. M.; FREIRE, S. E.; BAYÓN, N. D.; COLARES, M. N.; MONTI, C.; NOVOA, M. C.; HERNÁNDEZ, M. P. Morfoanatomía foliar de árboles medicinales de la Provincia Biogeográfica de las Yungas (Argentina). Bol. Latinoam. Caribe Plant. Med. Arom., Santiago, v. 8, n. 5, p. 342-379, 2009. 
BARRETO, M. A.; ALVES, V. F. G.; NEVES, L. J. Contribuição ao estudo de Vernonia condensata Baker. Rev. Bras. Farm., Rio de Janeiro, v. 75, n. 3, p. 54-58, 1994.

BERLYN, G. P.; MIKSCHE, J. P. Botanical microtechnique and cytochemistry. Ames: lowa State University Press, 1976. 326p.

FILIZOLA, L. R. S.; PIMENTEL, R. M. M.; RANDAU, K. P.; XAVIER, H. S. Anatomia dos órgãos vegetativos de Vernonia brasiliana (L.) Druce. Lat. Am. J. Pharm., La Plata, v. 22, n. 4, p. 299-303, 2003.

IPNI. International Plant Name Index. 07 Feb 2014 <http://www.ipni.org/ ipni/idPlantNameSearch.do;jsessionid=013C8B3ED3E4D0A7FC1787FF45B22F99? id=969234-1\&back_page=\%2Fipni\%2FeditSimplePlantNameSearch.do\%3Bjsession id\%3D013C8B3ED3E4D0A7FC1787FF45B22F99\%3Ffind_wholeName\%3Dvernona nthura\%2Btweedieana\%26output_format\%3Dnormal >.

IWALEWA, E. O.; IWALEWA, O. J.; ADEBOYE, J. O. Analgesic, antipyretic, antiinflammatory effects of methanol, chloroform and ether extracts of Vernonia cinerea Less. leaf. J. Ethnopharmacol., Limerick, v. 86, p. 229-234, 2003.

JOHANSEN, D. A. Plant microtechnique. New York: McGraw-Hill Book, 1940. 523p.

JORGE, L. I. F.; PEREIRA, U.; SILVA, A. M. Identificação histológica das principais compostas brasileiras de emprego medicinal. Rev. Inst. Adolfo Lutz, São Paulo, v. 51, n. 1/2, p. 47-51, 1991.

MACÊDO, N. A. Manual de técnicas em histologia vegetal. Feira de Santana: UEFS, 1997.68p.

MARODIN, S. M.; BAPTISTA, L. R. M. O uso de plantas com fins medicinais no município de Dom Pedro de Alcântara, Rio Grande do Sul, Brasil. Rev. Bras. PI. Med., Botucatu, v. 4, n. 1, p. 57-68, 2001.

METCALFE, C. R.; CHALK, L. Anatomy of the dicotyledons: leaves, stem, and wood in relation to taxonomy, with notes on economic uses. Oxford: Clarendon, 1950. 2v., $1500 p$.

MILAN, P.; HAYASHI, A. H.; APEZZATO-DA-GLÓRIA, B. Comparative leaf morphology and anatomy of three Asteraceae species. Braz. Arch. Biol. Technol., Curitiba, v. 49, n. 1, p. $135-144,2006$. 
MOBOT. Tropicos.org. Missouri Botanical Garden. 07 Feb 2014 <http://www.tropicos.org/Name/2740084>.

NERGARD, C. S.; DIALLO, D.; MICHAELSEN, T. E.; MALTERUD, K. E.; KIYOHARA, H.; MATSUMOTO, T.; YAMADA, H.; PAULSEN, B. S. Isolation, partial characterisation and immunomodulating activities of polysaccharides from Vernonia kotschyana Sch.Bip. ex Walp. J. Ethnopharmacol., Limerick, v. 91, p. 141-152, 2004.

O'BRIEN, T. P.; FEDER, N.; McCULLY, M. E. Polychromatic staining of plant cell walls by toluidine blue O. Protoplasma, Vienna, v. 59, n. 2, p. 368-373, 1964.

O'BRIEN, T. P.; FEDER, N.; McCULLY, M. E. Polychromatic staining of plant cell walls by toluidine blue O. Protoplasma, Vienna, v. 59, n. 2, p. 368-373, 1964.

PORTILLO, A.; VILA, R.; FREIXA, B.; FERRO, E.; PARELLA, T.; CASANOVA, J.; CAÑIGUERAL, S. Antifungal sesquiterpene from the root of Vernonanthura tweedieana. J. Ethnopharmacol., Limerick, v. 97, p. 49-52, 2005.

RABE, T.; MULLHOLLAND, D.; STADEN, J. Isolation and identification of antibacterial compounds from Vernonia colorata leaves. J. Ethnopharmacol., Limerick, v. 80, p. 9194, 2002.

REDONDA-MARTÍNEZ, R.; VILLASEÑOR, J. L.; TERRAZAS, T. Trichome diversity in the Vernonieae (Asteraceae) of Mexico. I: Vernonanthura and Vernonia (Vernoniinae). J. Torrey Bot. Soc., Lawrence, v. 139, n. 3, p. 235-247, 2012.

ROBINSON, H. A new genus Vernonanthura (Vernonieae, Asteraceae). Phytologia, Huntsville, v. 73, n. 2, p. 65-76, 1992.

ROESER, K. R. Die Nadel der Schwarzkiefer-Massenprodukt und Kunstwerk der Natur. Mikrokosmos, Stuttgart, v. 61, n. 2, p. 33-36, 1972.

SOARES, E. L. C.; VENDRUSCOLO, G. S.; EISINGER, S. M.; ZÁCHIA, R. A. Estudo etnobotânico do uso dos recursos vegetais em São João do Polêsine, RS, Brasil, no período de outubro de 1999 a junho de 2001. I. Origem e fluxo do conhecimento. Rev. Bras. PI. Med., Botucatu, v. 6, n. 3, p. 69-95, 2004.

SOUZA, W. Técnicas básicas de microscopia eletrônica aplicadas às Ciências Biológicas. Rio de Janeiro: Sociedade Brasileira de Microscopia Eletrônica, 1998. p. 144. 


\section{7-FIGURAS}
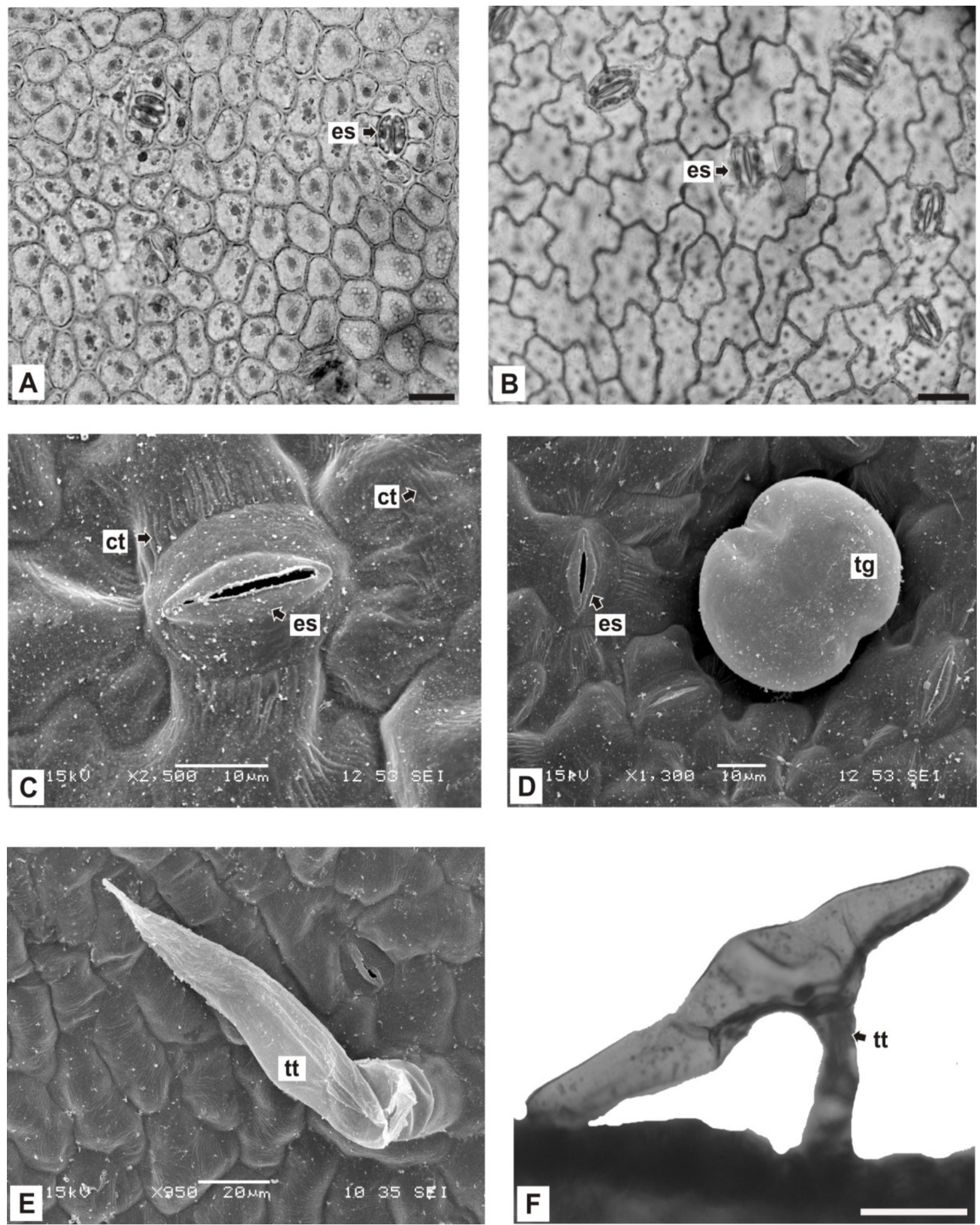

FIGURA 1A-F. Vernonanthura tweedieana (BAKER) H.ROB., ASTERACEAE, FOLHA: A, B. VISTA FRONTAL DA EPIDERME, FACES ADAXIAL E ABAXIAL, RESPECTIVAMENTE; C. PORMENOR DE UM ESTÔMATO E DA CUTÍCULA ESTRIADA; D-F. TRICOMAS EM DETALHE. ABREVIATURAS: ct CUTÍCULA, es - ESTÔMATO, tg - TRICOMA GLANDULAR, tt - TRICOMA TECTOR. BARRA $=20 \mu \mathrm{m}$ $(A, B, F)$ 

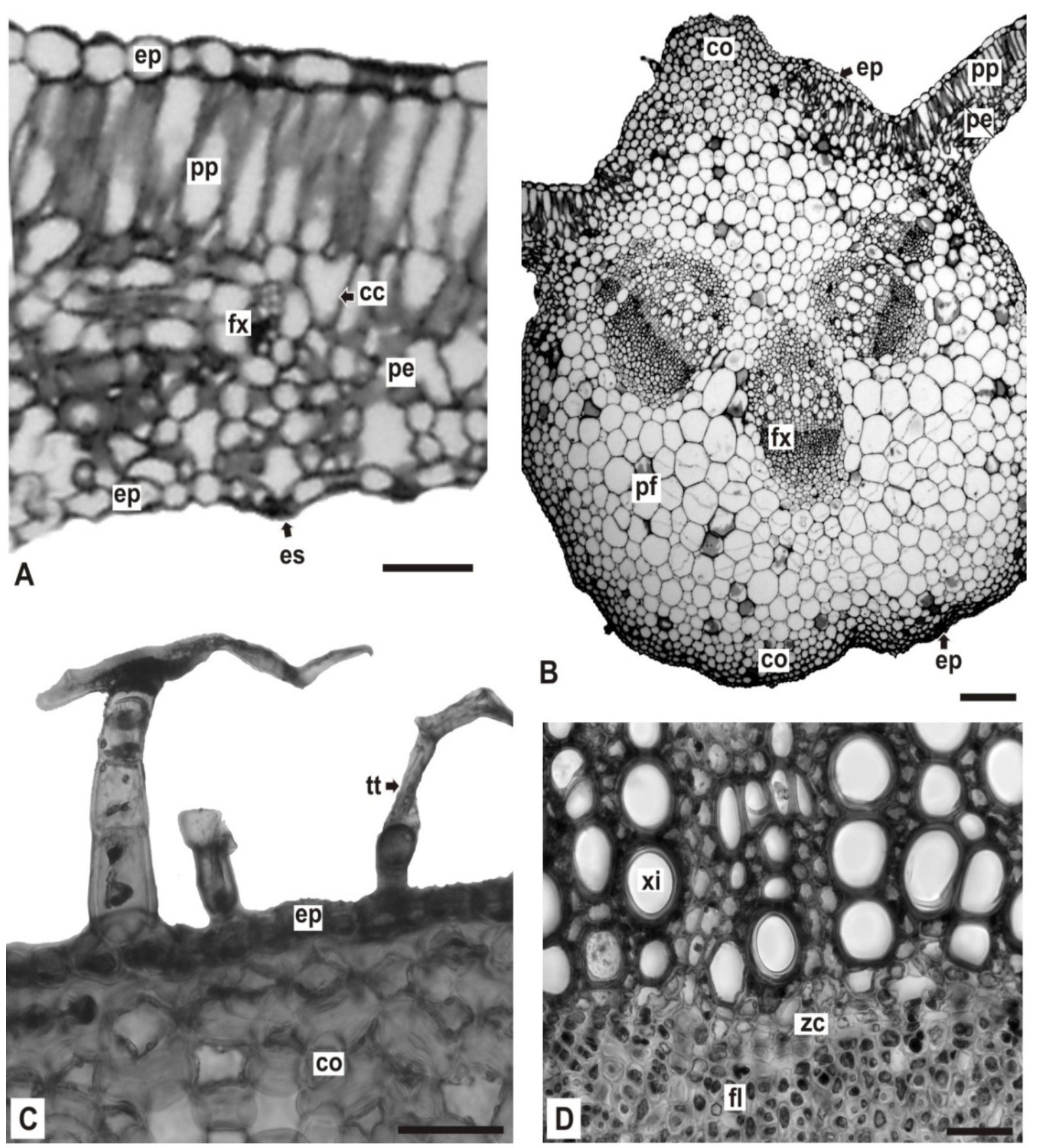

FIGURA 2A-D. Vernonanthura tweedieana (BAKER) H.ROB., ASTERACEAE, FOLHA EM SECÇÃO TRANSVERSAL: A. REGIÃO INTERNERVURAL, MOSTRANDO EPIDERME UNISSERIADA, MESOFILO DORSIVENTRAL E FEIXE VASCULAR DE PEQUENO PORTE; B. ASPECTO DA NERVURA CENTRAL E DE PARTE DA REGIÃO INTERNERVURAL; C. TRICOMAS TECTORES E COLÊNQUIMA ANGULAR JUNTO DA SUPERFÍCIE ADAXIAL DA NERVURA CENTRAL; D. PORMENOR DE UM FEIXE VASCULAR COLATERAL. ABREVIATURAS: cc - CÉLULA COLETORA, co - COLÊNQUIMA, ep - EPIDERME, es - ESTÔMATO, fl - FLOEMA, fx - FEIXE VASCULAR, pe PARÊNQUIMA ESPONJOSO, pf - PARÊNQUIMA FUNDAMENTAL, pp - PARÊNQUIMA PALIÇÁDICO, $\mathbf{x i}-\mathrm{XILEMA}, \mathbf{z c}-Z \mathrm{ZONACAMBIAL}$. BARRA $=100 \mu \mathrm{m}(\mathrm{B}), 20 \mu \mathrm{m}(\mathrm{A}, \mathrm{C}, \mathrm{D})$ 

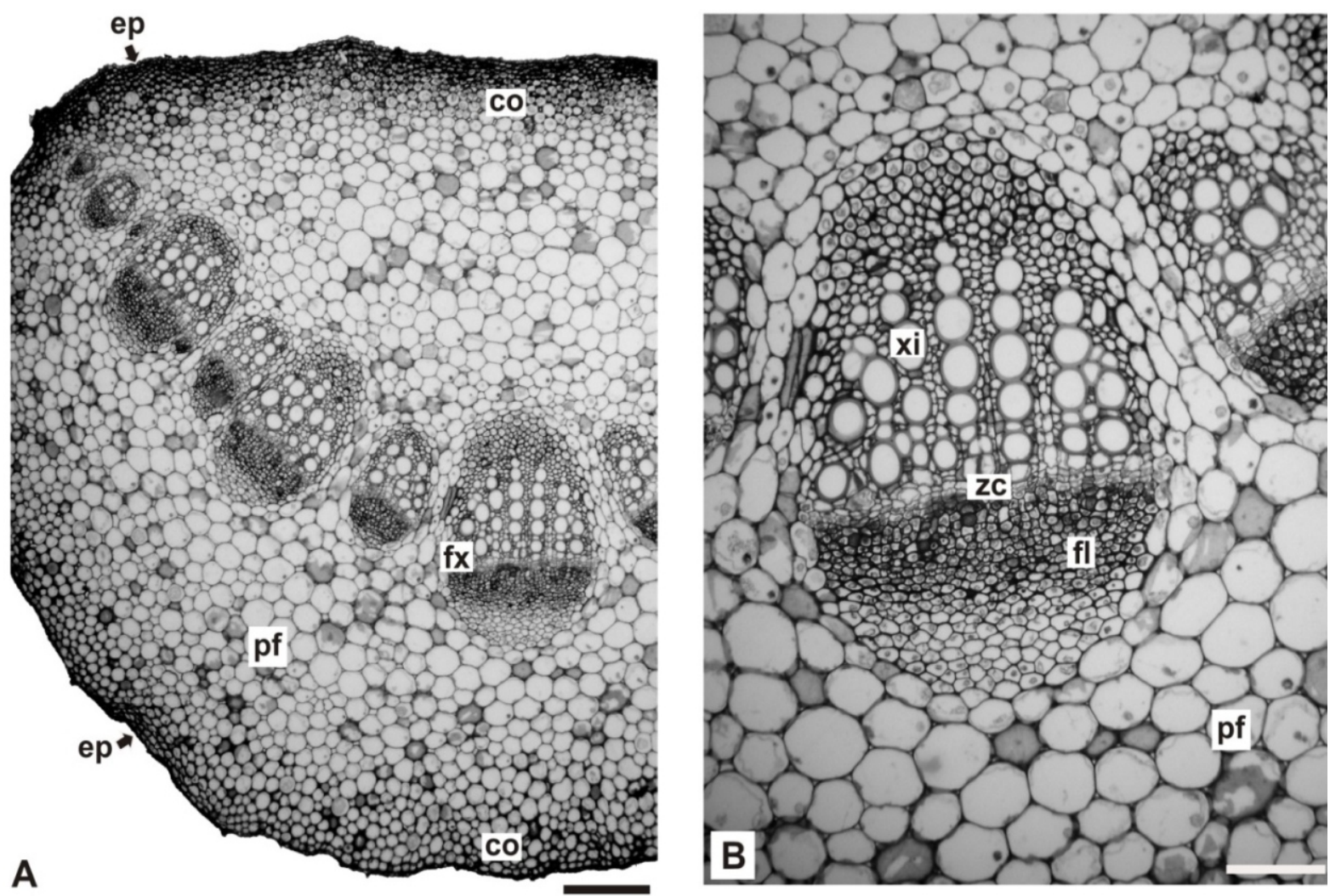

FIGURA 3A-D. Vernonanthura tweedieana (BAKER) H.ROB., ASTERACEAE, PECÍOLO EM SECÇÃO TRANSVERSAL: A. ORGANIZAÇÃO GERAL; B. DETALHE DE UM FEIXE VASCULAR. ABREVIATURAS: co - COLÊNQUIMA, ep - EPIDERME, fl - FLOEMA, fx - FEIXE VASCULAR, pf PARÊNQUIMAFUNDAMENTAL, $\mathbf{x i}-\mathrm{XILEMA,} \mathrm{zc}-Z O N A C A M B I A L$. BARRA $=100 \mu \mathrm{m}(\mathrm{A}), 50 \mu \mathrm{m}(\mathrm{B})$ 